\title{
ANALYSIS OF THE LOCAL AND GENERAL RESISTANCE OF THE STRUCTURE OF A CARGO TANK
}

\author{
Anişoara - Gabriela Cristea \\ "Dunarea de Jos" University of Galati, \\ Faculty of Naval Architecture, Galati, Domneasca \\ Street, No. 47, 800008, Romania, \\ E-mail: anisoara.cristea@ugal.ro
}

\author{
Grosu Alexandru \\ "Dunarea de Jos" University of Galati, \\ Faculty of Naval Architecture, Galati, Domneasca \\ Street, No. 47, 800008, Romania, \\ E-mail: alexandru.grosu97@yahoo.com
}

\begin{abstract}
The purpose of this paper is to verify the induced stresses of a framework element from central area of the chemical tanker ship type. This static calculation was performed by the finite element method with Femap software as modeler and NX Nastran as solver.
\end{abstract}

Keywords: hydrostatic water pressure, stress calculation, mechanical structural, finite element method.

\section{PURPOSE OF THE STUDY}

The analysis has the purpose to determine the stresses that will occur in the structure of the vessel in the most unfavorable conditions. Afterwards intervention will be made upon the structure to ensure the resistance of the vessel, according to the registrar company Det Norske Veritas Germanischer Lloyd, by optimization of the elements of the framing system in the areas where the maximum allowable stresses are exceeded. The analysis will be performed for a single cargo tank, for static stress cases, in which the vessel will be placed on still water, on sagging and hogging.

\section{GENERATING AND ANALYSIS OF THE MODEL}

The FEMAP program is used to generate the cargo tank model and mesh. The FEMAP/NX NASTRAN software package, from UGS Corporation/Siemens PLM Software Inc., is an integrated analysis system by method of finite elements. The program includes modules for solving linear and nonlinear structural problems, static and dynamic, as well as heat transfer problems. The FEMAP/NX NASTRAN system contains pre/postprocessing modules, analysis and utility modules. The FEMAP module represents the pre/postprocessing module, including an interactive CAD/ FEM modeler and NX NASTRAN represents the FEM solver. The GEOMETRY menu contains commands for generating and processing geometric objects, which is the CAD model. Based on the CAD model, the FEM model can be generated parametrically or automatically using the commands in the MESH.14 menu. The model is made on a cargo tank, between frame 64 and frame 82, in a single board. The structure is simplified by eliminating brackets and stiffening ribs, but also by simplifying the simple framing system, from bulb profiles (HP) to flat band profiles (FB). The cargo tank is modeled directly in the FEMAP program using the integrated $\mathrm{CAD}$ modeler.

The structure is modeled in the program with the following dimensions, presented in Table 1.1, following the sampling from the central area (Fig.1.1) generated in the POSEIDON program. In the Table below hwmax is the maximum height of the wave that will be used to analyze the structure, aL is 
the intercostal distance, $\mathrm{aF}$ is the distance between two floors, and Dpp and Dpv are the stern and bow drafts, they have equal values to simulate the right trimming of the vessel.

Tabe 1.1 The main characteristics of the oil tanker (simplified structure)

\begin{tabular}{|l|l|}
\hline $\mathrm{L}=118.160 \mathrm{~m}$ & $\rho_{\mathrm{otel}}=8 \mathrm{E}-6 \mathrm{~kg} / \mathrm{mm}^{3}$ \\
\hline $\mathrm{B}=18.5 \mathrm{~m}$ & $\mathrm{aL}=0.8 \mathrm{~m}$ \\
\hline $\mathrm{D}=10 \mathrm{~m}$ & $\mathrm{aF}=2.4 \mathrm{~m}$ \\
\hline Lmag. $=14.4 \mathrm{~m}$ & $\mathrm{D}_{\mathrm{pp}}=7.4 \mathrm{~m}$ \\
\hline $\mathrm{x}_{\mathrm{mp}} \mathrm{p}=52 \mathrm{~m}$ & $\mathrm{D}_{\mathrm{pv}}=7.4 \mathrm{~m}$ \\
\hline $\mathrm{h}_{\mathrm{w}}=6.1 \mathrm{~m}$ & $\begin{array}{l}\text { Number of nodes }= \\
152242\end{array}$ \\
\hline $\begin{array}{l}\text { Young's modulus } \\
\mathrm{E}=2.06 \mathrm{E}+5 \mathrm{~N} / \mathrm{mm}^{2}\end{array}$ & $\begin{array}{l}\text { Number of elements } \\
=155497\end{array}$ \\
\hline $\begin{array}{l}\text { Poisson's ratio } v= \\
0.3\end{array}$ & \\
\end{tabular}

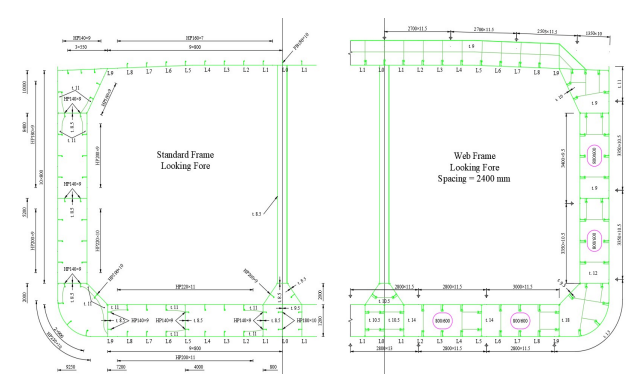

Fig. 1.1 Cross-section area at the amidships section

Before generating the FEM model, the used material and the properties of the plates and profiles used in the studied structure will be defined. The used material is grade A steel, with a material density of $8 \mathrm{t} / \mathrm{m}^{3}$, with a yield strength of $235 \mathrm{~N} / \mathrm{mm}^{2}$ and a breaking strength of $400 \mathrm{~N} / \mathrm{mm}^{2}$. The other characteristics of the material are shown in Table 1.2. The properties of the plates and profiles introduced in the program define the thickness of each structural element used in the model.

In the FEM model, plate type elements (PLATE - Mindlin) are used implemented in the FEM program. Most elements are quadrilaterals, but if they cannot be used, triangular elements are used. The variation of the shapes and sizes of the elements in the FEM model occurs due to the different dimensions of the longitudinal profiles and their positions.

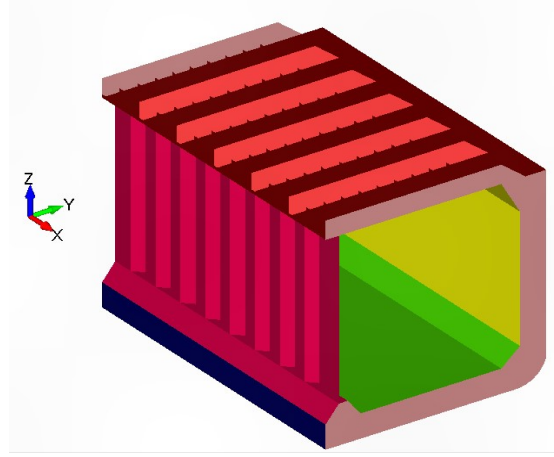

Fig. 1.2 CAD model - cargo tank

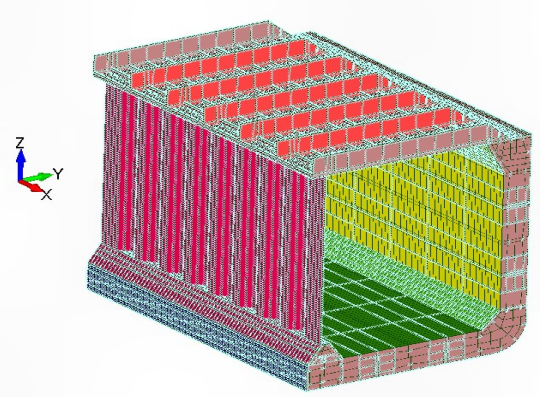

Fig. 1.3 FEM model - cargo tank

\section{EDGE CONDITIONS}

As the loads of the model are made of quasi-static equivalent waves or still water, the stresses of the model are only vertical symmetrical in relation to the diametrical plane of the hull. The edge conditions applied on the $\mathrm{FEM}^{[5]}$ model have the role of simulate the existence of real structure of the vessel in the aft, in the fore and in the opposite board of the shaped bowlocker.

For the study of the current model, ordinary edge conditions will be used, these are shown in Table 1.2. 
Table 1.2 Boundary conditions for the 3D - FEM model

\begin{tabular}{|c|c|c|c|c|c|c|}
\hline \multirow{2}{*}{$\begin{array}{c}\text { Boundary } \\
\text { condition }\end{array}$} & \multicolumn{5}{|c|}{ Blocked degrees of freedom } \\
\cline { 2 - 7 } & $\mathrm{T}_{\mathrm{x}}$ & $\mathrm{Ty}$ & $\mathrm{T}_{\mathrm{z}}$ & $\mathrm{Rx}$ & $\mathrm{Ry}$ & $\mathrm{Rz}$ \\
\hline $\begin{array}{c}\text { Symmetry in } \\
\text { the diametral } \\
\text { plane PD }\end{array}$ & - & $\mathrm{x}$ & - & $\mathrm{x}$ & - & $\mathrm{x}$ \\
\hline $\begin{array}{c}\text { Stern master } \\
\text { node NDpp }\end{array}$ & $\mathrm{x}$ & $\mathrm{x}$ & $\mathrm{x}$ & $\mathrm{x}$ & - & $\mathrm{x}$ \\
\hline $\begin{array}{c}\text { Stern master } \\
\text { node NDpv }\end{array}$ & - & $\mathrm{x}$ & $\mathrm{x}$ & $\mathrm{x}$ & - & $\mathrm{x}$ \\
\hline
\end{tabular}

In conclusion, from the above Table, we have the condition of symmetry applied on all nodes in the area where the symmetrical hatch is missing from the board opposite the model, the transverse movement and rotation being blocked along the longitudinal axis. The edge condition at the aft of the model allows only rotation along the transverse axis, and the edge condition at the bow of the model allows only longitudinal movement and rotation along the transverse axis (Fig. 1.4).

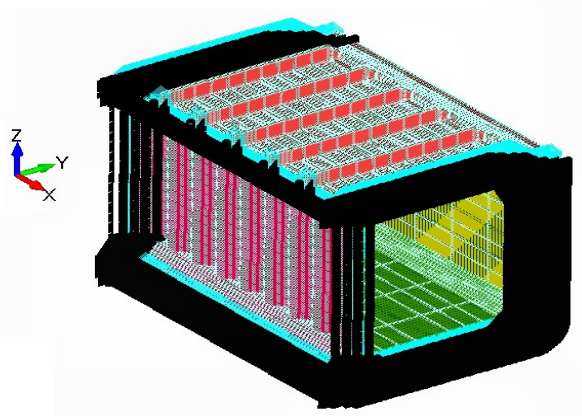

Fig. 1.4 Boundary conditions for the 3D FEM model

\subsection{Loads applied upon the model}

The FEM model is subjected to the following types of loads:

$\checkmark$ Gravitational load:

It is defined by the own weight of the structural elements of the vessel, $\mathrm{g}=9.81$ $\mathrm{m} / \mathrm{s}^{2}, \rho_{\text {steel }}=8 \mathrm{t} / \mathrm{m}^{3}$, and other components on board of the vessel in the area of the modeled cargo tank.

(C) Galati University Press, 2020 $\checkmark \quad$ Cargo loading (vegetable oils):

The hydrostatic pressure $\left[\mathrm{N} / \mathrm{mm}^{2}\right]$ generated by the cargo, $\rho_{\text {cargo }}=0.93 \mathrm{t} / \mathrm{m}^{3}$, is applied to the double bottom shell, the double board shell and the longitudinal wall. The cargo tank is loaded up to a height of 9 meters, to simulate the case of full loading. (Fig.1.5)

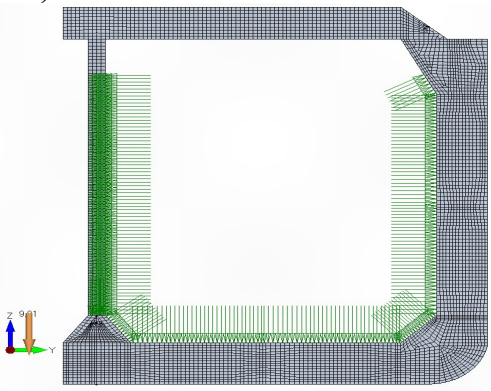

Fig. 1.5 Hydrostatic cargo pressure distribution $\left(\rho_{\text {cargo }}=0.93 \mathrm{t} / \mathrm{m}^{3}\right)$

The maximum loading height of the cargo in tanks was calculated at the stage of the general arrangement of the vessel, together with the calculation of the volumes of fluids on board of the vessel, to ensure the draft at full load and to ensure the draught of ballast.

$\checkmark \quad$ Loading from still water:

$\checkmark \quad$ The hydrostatic pressure [N/mm $\left.{ }^{2}\right]$ generated by the still water, $\rho_{\text {water }}=1,025 \mathrm{t} / \mathrm{m}^{3}$, is applied on the shell of the vessel, up to the height of the full load draft of 7.4 meters (Fig. 1.6).

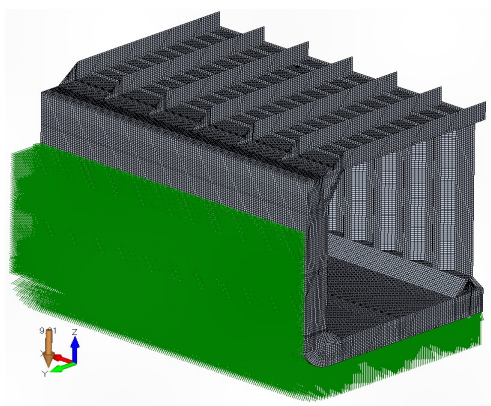

Fig. 1.6 Hydrostatic pressure generated by the still water $\left(\rho_{\text {water }}=1,025 \mathrm{t} / \mathrm{m}^{3}\right)$ 
Loading from the equivalent quasi-static meeting wave, with Smith correction:

Two cases of loading will be defined: sagging (Fig. 1.7) and hogging of wave (Fig. 1.8). In order to determine the height of the wave used to define the loads, the relation given by the classification company DNV GL for vessels smaller than 270 meters is used:

$$
h_{w}=1.25 \sqrt[3]{\lambda}
$$

Where $\lambda$, the length of the wave, is considered equal to the length of the vessel, to consider the most unfavorable case.

Following the calculation, the height of the wave used for the analysis on the sagging and hogging will be 6.1 meters.

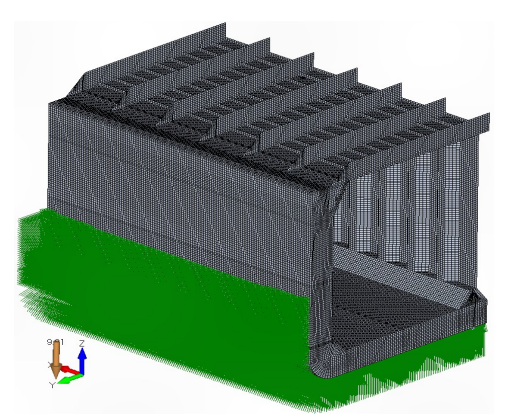

Fig. 1.7 Hydrostatic loading for the case of the ship on the wave sagging

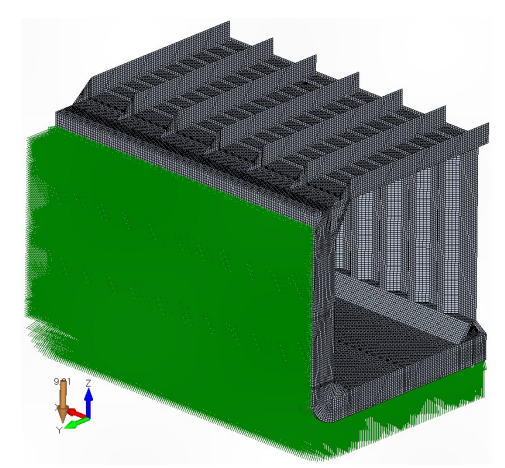

Fig. 1.8 Hydrostatic loading for the case of the ship on the wave hogging

\section{RESULTS OBTAINED FROM THE FINITE ELEMENT ANALYSIS}

Following the analysis, the maximum allowable stresses that appear on the structure after the FEM analyzes will be checked. The stresses appearing on the model must be compared with the maximum values accepted by the IMO, by the Common Structural Rules Convention, for vessels with $\mathrm{L} \geq 150$ $\mathrm{m}$ and for vessels with $\mathrm{L}<150 \mathrm{~m}$ will be compared with the values imposed by the used classification company.

For the studied vessel the rules of the classification company DNV GL, shown in Part 3, Chapter 7, Section 3 (Table 1.3) will be used.

Tabel 1.3 Permissible coarse mesh yield uti-

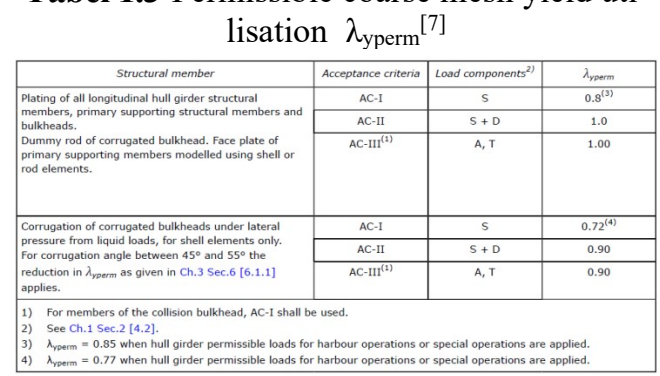

From the above Table, the allowable stress for the plates and profiles used in the structure will be calculated, in the case of static analysis, by multiplying the flow limit of the material to $\lambda_{\text {yperm }}=0.8$. And for the corrugated wall, the flow limit of the material is multiplied by $\lambda_{\text {yperm }}=0.72$. The $\lambda$ yperm factor for the corrugated wall is reduced by $10 \%$, according to DNV GL, Part 3, Chapter 3 , Section 6, Rule 6.1.1, because the angle of the corrugations is $45^{\circ}$.

Following the calculations, we have the following values of allowable stresses for steel with flow limit $235 \mathrm{~N} / \mathrm{mm}^{2}$ :

$\checkmark \quad$ For plates and profiles, the average stress in the element shall not exceed $188 \mathrm{~N} /$ $\mathrm{mm}^{2}$; 
$\checkmark$ For the corrugated wall, the average stress in the element induced by the lateral pressure of the goods shall not exceed 152.3 $\mathrm{N} / \mathrm{mm}^{2}$.

When interpreting the analyzes, the maximum stresses in the structure and the average stresses per element will be taken into account.

From the analysis in still water, from Fig. 1.9, it is observed that the allowable stresses are exceeded on the corrugated wall, on the stool and on the longitudinal profiles on the bottom and double bottom.

Thus, following several analyzes, the thicknesses and materials used for certain elements in the structure of the cargo tank will be changed:

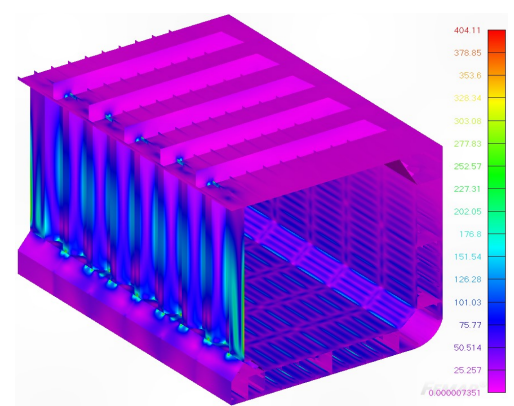

Fig. 1.9 Analysis results in calm water, maximum stresses

$\checkmark \quad$ At the corrugated wall the thickness of the plate changes from $8.5 \mathrm{~mm}$ to $17.5 \mathrm{~mm}$;

$\checkmark$ At the lower stool below the longitudinal wall, the steel with a flow limit of $235 \mathrm{~N} /$ $\mathrm{mm}^{2}$ is changed with a steel with a flow limit of $355 \mathrm{~N} / \mathrm{mm}^{2}$ and the plate thickness from $8.5 \mathrm{~mm}$ to $9.5 \mathrm{~mm}$;

$\checkmark \quad$ For the profiles on the bottom and double bottom, the used profile is changed from 200x11 and 220x11 to 200x13 and 220x13.

Following the calculations in Fig. 1.10 we have the following values of allowable stresses for steel with flow limit $355 \mathrm{~N} / \mathrm{mm}^{2}$, used in stool:

$\checkmark$ For stool, the average stress in the element will not exceed $284 \mathrm{~N} / \mathrm{mm}^{2}$. $\checkmark$

(C) Galati University Press, 2020

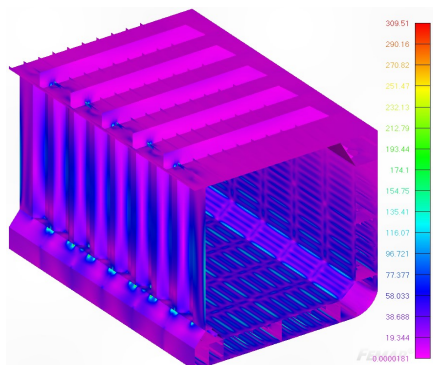

Fig. 1.10 Analysis results in calm water after changes, maximum stresses

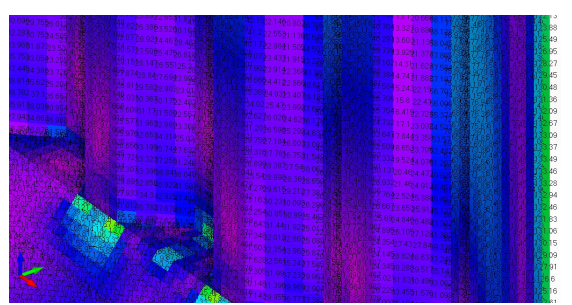

Fig. 1.11 The average stress per element, in the area of the corrugated wall at the fore of the model

In Fig. 1.11 it is observed that, in still water, the average stress per element, in the area of the corrugated wall at the fore of the model, does not exceed the allowable stress of $152.3 \mathrm{~N} / \mathrm{mm}^{2}$. The maximum value on the wall is $133.49 \mathrm{~N} / \mathrm{mm}^{2}$.

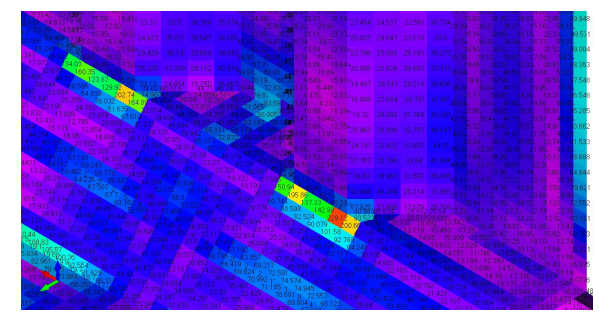

Fig. 1.12 The average stress per element, in the area of the stool at the aft of the model (still water)

In Fig. 1.12 it is observed that, in still water, the average stress per element, in the area of the stool at the aft of the model, does not exceed the allowable stress of $284 \mathrm{~N} / \mathrm{mm}^{2}$. The maximum value per stool is $229.12 \mathrm{~N} / \mathrm{mm}^{2}$. 


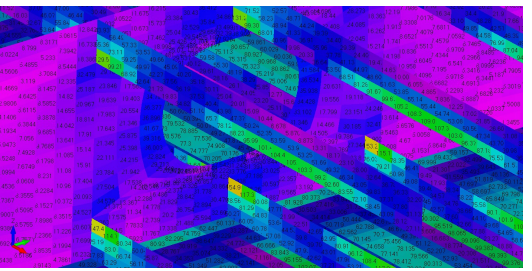

Fig. 1.13 The average stress per element, in the area of the double bottom section at the bow of the model

In Fig. 1.13 it is observed that, in still water, the average stress per element, in the area of the double bottom section at the bow of the model, does not exceed the allowable stress of $188 \mathrm{~N} / \mathrm{mm}^{2}$. High values appear on the longitudinal bottom profiles in the vicinity of the heart pattern floor-plate. The maximum value in this area is $154.97 \mathrm{~N} / \mathrm{mm}^{2}$.

The analyzes for the sagging and hogging cases will be performed using the model in which the elements have been modified.

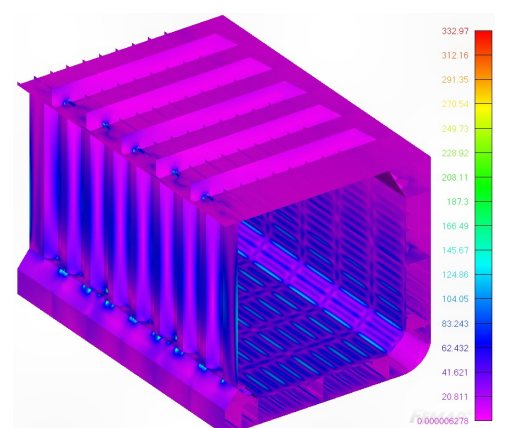

Fig. 1.14 Stress VonMises - sagging

From the results of the sagging analysis, Fig. 1.14, it is observed that the maximum stresses are below the values of the material flow limits, $155 \mathrm{~N} / \mathrm{mm}^{2}$ on the corrugated wall, $333 \mathrm{~N} / \mathrm{mm}^{2}$ on the stool, respectively 160 $\mathrm{N} / \mathrm{mm}^{2}$ on the longitudinal profiles on the double bottom and on the double bottom coating.

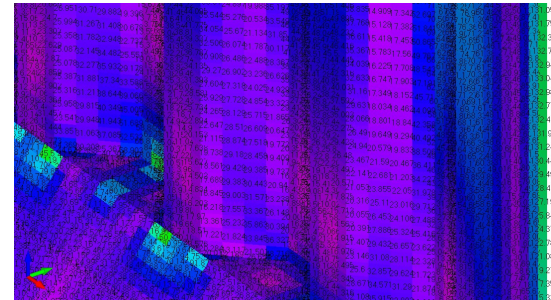

Fig. 1.15 The average stress per element, in the area of the corrugated wall at the bow of the model (sagging)

In Fig. 1.15 it is observed that, on the sagging, the average stress per element, in the area of the corrugated wall at the bow of the model, does not exceed the allowable stress of $152.3 \mathrm{~N} / \mathrm{mm}^{2}$. The maximum value on the wall is $132.94 \mathrm{~N} / \mathrm{mm}^{2}$.

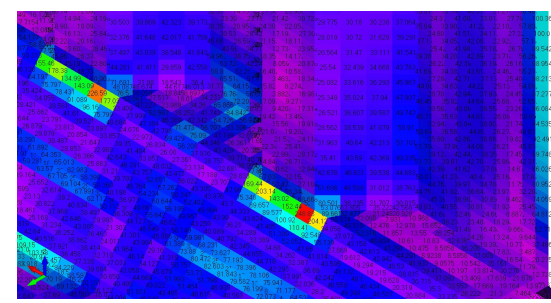

Fig. 1.16 The average stress per element, in the area of the stool at the aft of the model (sagging)

In Fig. 1.16 it is observed that, on the sagging, the average stress per element, in the area of the stool at the aft of the model, slightly exceeds the allowable stress of 284 $\mathrm{N} / \mathrm{mm}^{2}$. The maximum value per stool is $248.83 \mathrm{~N} / \mathrm{mm}^{2}$.

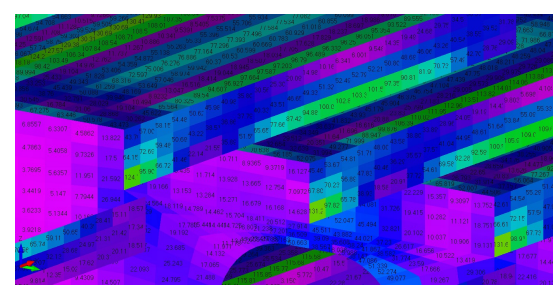

Fig. 1.17 The average stress per element, in the area of the double bottom section at the bow of the model (sagging) 
In Fig. 1.17 it is observed that, on the sagging, the average stress per element, in the area of the double bottom section at the bow of the model, does not exceed the allowable stress of $188 \mathrm{~N} / \mathrm{mm}^{2}$. High values appear on the double bottom shell and on the longitudinal double bottom profiles in the vicinity of the heart pattern floor-plate. The maximum value in this area is 131.64 $\mathrm{N} / \mathrm{mm}^{2}$.

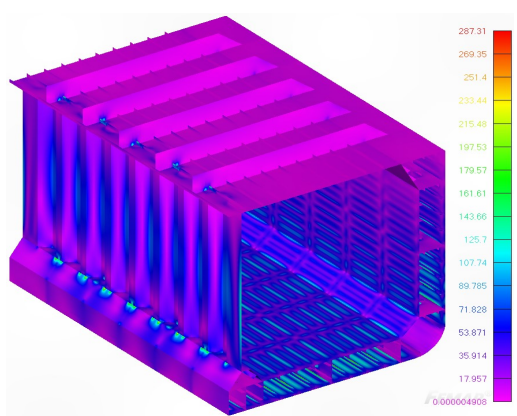

Fig. 1.18 Stress VonMises (hogging)

From the results of the analysis on the wave ridge, Fig. 1.18, it is observed that the maximum stresses are below the values of the material flow limits, $160 \mathrm{~N} / \mathrm{mm}^{2}$ on the embossed wall, $287.3 \mathrm{~N} / \mathrm{mm}^{2}$ on the stool, respectively $230 \mathrm{~N} / \mathrm{mm}^{2}$ on the longitudinal profiles on the double bottom and on the double bottom coating.

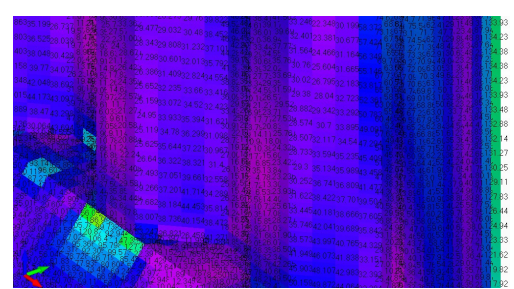

Fig. 1.19 The average stress per element, in the area of the corrugated wall at the bow of the model (hogging)

In Fig. 1.19 it is observed that, on the hogging, the average stress per element, in the area of the corrugated wall at the bow of the model, does not exceed the allowable stress of $152.3 \mathrm{~N} / \mathrm{mm}^{2}$. The maximum value on the wall is $134.38 \mathrm{~N} / \mathrm{mm}^{2}$.

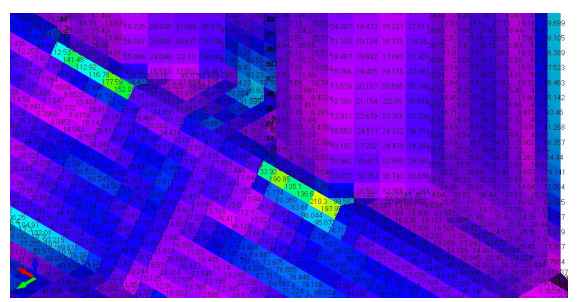

Fig. 1.20 The average stress per element, in the area of the stool at the aft of the model (hogging)

In Fig. $\mathbf{1 . 2 0}$ it is observed that, on the hogging, the average stress per element, in the area of the stool at the aft of the model, slightly exceeds the allowable stress of 284 $\mathrm{N} / \mathrm{mm}^{2}$. The maximum value per stool is $210.3 \mathrm{~N} / \mathrm{mm}^{2}$.

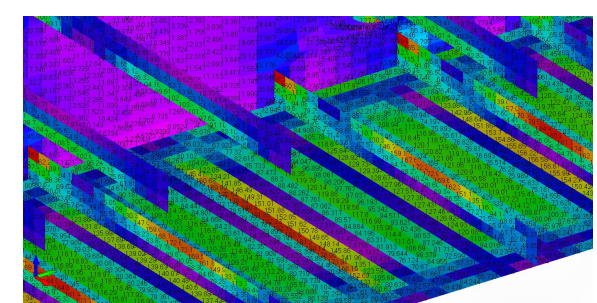

Fig. 1.21 The average stress per element, in the area of the double bottom section at the bow of the model (hogging)

In Fig. 1.21 it is observed that, on the hogging, the average stress per element, in the area of the double bottom section at the bow of the model, exceeds the allowable stress of $188 \mathrm{~N} / \mathrm{mm}^{2}$. The values Bthat exceed the allowable stress appear on the longitudinal bottom profiles in the vicinity of the heart pattern floor-plate, respectively in the middle of the profile between 2 floors. The maximum value on the profiles is 219.95 $\mathrm{N} / \mathrm{mm}^{2}$. 


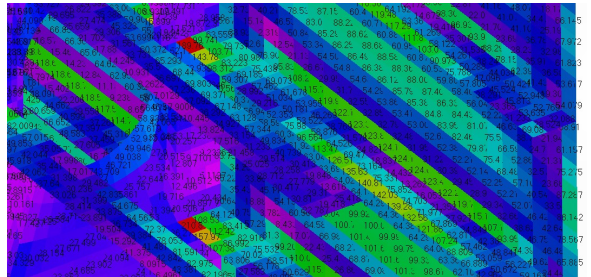

Fig. 1.22 The average stress per element, in the area of the double board section at the bow of the model (hogging)

In Fig. 1.22 it is observed that, on the hogging, the average stress per element, in the area of the double board section at the bow of the model, exceeds the allowable stress of $188 \mathrm{~N} / \mathrm{mm}^{2}$. The values that exceed the allowable stress appear on the longitudinal board profiles in the vicinity of the heart pattern floor-plate. The maximum value in this area is $210.8 \mathrm{~N} / \mathrm{mm}^{2}$.

\section{CONCLUSIONS}

In conclusion, from the following analyzes we can see that following the changes on the structure, the stresses that appear in the model for the analysis in still water and sagging are satisfactory according to the classification company DNV GL. For analysis on the hogging, where the highest values appear that exceed the allowable stresses imposed by the rules, the excessive stresses can be easily reduced using stiffening ribs on floors, elements that are missing from the analyzed FEM model to simplify it.

In all areas where higher stresses occur compared to the rest of the model, it is possible to intervene on the structure with elements with relatively low costs, but positively influence the resistance of the vessel.
For the double bottom section, the double board section and in the stool area, it is recommended to use the stiffening elements welded on the floors in the continuation of the longitudinal profiles, the flat strips welded in the cutting area and the brackets in the simple frame area.

A particular case occurs in the corrugated wall, because its optimization can be more efficient by changing the angle of the corrugations, from $45^{\circ}$ to $55^{\circ}$ or more.

\section{REFERENCES}

[1] Cristea A.G., Determination of the induced stresses at the level of a floor using the finite element method, Editura Nautica, Constanţa, 2010 [2] Cristea A.G., Contribuții privind optimizarea structurilor de navă, Teză de doctorat, Galați, 2014

[3] Domnişoru L., Metoda elementului finit în construcţii navale. Aplicaţii, Editura Evrika, Brăila, 2003

[4] Domnişoru L., Găvan E., Popovici O., Analiza structurilor navale prin metoda elementului finit. Editura Didactică şi Pedagogică, Bucureşti, 2005

[5] Domnişoru L., Analiza structurilor navale prin metoda elementului finit . Aplicatii numerice, Editura Fundaţiei Universitare "Dunărea de Jos", Galaţi, 2009

[6] $\mathbf{x} \mathbf{x} \mathbf{x}$ - FEMAP 12.0.1a / NX NASTRAN User's Guide, UGS Corporation / Siemens PLM Software Inc., 2019

[7] x x x - DNV GL, Part 3, Chapter 7, Section 3, 2020

[8] x x x - „Common Structural Rules for Bulk Carriers and Oil Tankers", 1 Jan. 2020, http://www.iacs.org.uk/publications/commonstructural-rules/csr-for-bulk-carriers-and-oiltankers/

Paper received on October $31^{\text {th }}, 2020$ 